\title{
Computer-Based Design of an HLA-Haplotype and HIV-Clade Independent Cytotoxic T-Lymphocyte (CTL) Assay for Monitoring HIV-Specific Immunity
}

\author{
Massimo Amicosante, ${ }^{1}$ Cristiana Gioia, ${ }^{1}$ Carla Montesano, ${ }^{1}$ Rita Casetti, ${ }^{1}$ Simone Topino, ${ }^{2}$ \\ Gianpiero D'Offizi, ${ }^{2}$ Giulia Cappelli, ${ }^{5}$ Giuseppe Ippolito, ${ }^{3}$ Vittorio Colizzi, ${ }^{4,5,6}$ Fabrizio Poccia, $^{1}$ \\ and Leopoldo P. Pucillo ${ }^{1}$ \\ ${ }^{1}$ Laboratory of Clinical Pathology \\ ${ }^{2}$ IV Clinical Division of Infectious Disease \\ "“Centro di Riferimento AIDS e Servizio di Epidemiologia delle Malattie Infettive” \\ ${ }^{4}$ International Center for AIDS, Emerging and Re-emerging Infections-UNESCO, of the National Institute \\ for Infectious Disease, "Lazzaro Spallanzani," Rome, Italy \\ ${ }^{5}$ Centre Integre de Recherches Biocliniques d'Abidjan (CIRBA), Abidjan, Ivory Coast \\ ${ }^{6}$ Department of Biology, University of Rome “Tor Vergata," Rome, Italy \\ Accepted October 10, 2002
}

\begin{abstract}
Background: Human immunodeficiency virus (HIV)specific CD8-positive cytotoxic T-lymphocytes (CTL) play a key role in controlling HIV infection. Monitoring CTL response could be clinically relevant during structured therapy interruption (STI), HIV exposure, and vaccine trials. However, HLA patients' restriction and HIV variability limited the development of a CTL assay with broad specificity.

Materials and Methods: We designed an HLA-class I/HIV-1 clade independent assay for assessing HIVspecific CTL by using a computer-assisted selection of the CTL epitopes. Twenty-eight 15-mers were selected by peptide-binding motifs analysis using different databases (HIV-Immunology Database, SYFPEITHI, BIMAS). Altogether they putatively bind to more than $\mathbf{9 0 \%}$ of HLA haplotypes in different populations, with an overall HIV-1 variability below $9 \%$. The peptide pool was used as an antigen in an intracellular cytokine
\end{abstract}

staining (ICS) assay for quantifying HIV-specific CTL response.

Results: The test can be performed using both fresh and cryopreserved peripheral blood mononuclear cells (PBMC), whereas GAG protein as antigen works only on fresh PBMC. A significantly higher CTL response with respect to HIV-negative controls was detected in all HIV-1 infected subjects of two groups of patients with different ethnicities (Caucasians and Africans) and coming from areas with different HIV-1 clade prevalences (clade B and A/G, respectively). In Caucasian patients, after month of STI, the number of HIV-1 specific CTL $(2896 \pm 2780$ IFN- $\gamma$ specific CD 8 cells/ml) was significantly higher than that found at enrolment $(2125 \pm 4426$ IFN- $\gamma$ specific CD8 cells/ml, $p<0.05)$. Conclusions: These data indicate that this CTL assay is broadly specific and could represent a useful clinical tool for HIV immunodiagnostic independent of HLA-haplotype and HIV-clade variabilities.

\section{Introduction}

Human immunodeficiency virus (HIV)-specific cytotoxic $\mathrm{T}$ lymphocytes (CTL) play a key role in the control of viremia and consequent long-term survival from acquired immunodeficiency syndrome (AIDS) (see McMichael et al. for review [1]). Failure to control viremia, in either primary or chronic infection, may be associated with escape mutations arising within immunodominant epitopes (1-5). Moreover, HIV-specific CTL cell responses decline

Address correspondence and reprint requests to: Massimo Amicosante, Laboratory of Clinical Pathology, I.N.M.I.

“L. Spallanzani," I.R.C.C.S., Via Portuense 292, I-00149 Rome, Italy. Phone: 39-06-55170-907; fax: 39-06-55170-904;

e-mail: amicosante@inmi.it. after highly active antiretroviral therapy (HAART)induced viral inhibition and are significantly increased by the viral rebound, consequent to therapy interruption $(6,7)$. Finally, anti-HIV-specific CTL response has been reported in healthy (HIV-negative) contacts of HIV-infected subjects (8-10). Thus, fine measuring of CTL responses against HIV could be useful in monitoring the patient's immune status during HIV infection, as well as in assessing the anti-HIV-specific CTL response in healthy subjects in particular risk groups.

Early analyses of CTL responses to HIV were measured by a limiting dilution technique where $\mathrm{T}$ lymphocytes responding to HIV were cloned and counted through a cumbersome process (11). In contrast, the recent development of more sensitive CTL 
assays allows a rapid quantification of antigen-specific CTL responses. Intracellular cytokine staining (ICS), MHC class I tetramer staining and ELIspot assays may allow a precise assessment of HIV-specific T-cell function and frequency (12-15). In this context, ICS is more sensitive than ELIspot analysis (16) and, like the tetramer assay, allows the simultaneous phenotypic analysis of the responding cells. Moreover, ICS can provide quantitative, functional, and phenotypic assessment of $\mathrm{CD}^{+} \mathrm{T}$ cells, whereas tetramer analysis is unable to provide a functional analysis and is usually restricted to a single peptide epitope. Finally, ICS only requires that whole proteins or peptide antigens are added to the cells, allowing the simultaneous analysis of both MHC class I and II restricted T-cell responses (17). Thus, ICS represent the ideal assay to monitor the functional reactivity of HIV-specific CTL in a broad range of individuals.

In the study of CTL-specific responses, a strong limitation is imposed by the restriction of the subject HLA haplotypes $(1,18)$. In this context, it is worth noting that the response to a single immunodominant HIV epitope recognized by an HLA allele is not always present in subjects carrying that allele, but other HIV epitope responses restricted by other subject HLA class I alleles could be present (13). Moreover, in most infected individuals the $\mathrm{CD} 8^{+} \mathrm{T}$-cell response to HIV is broad with multiple epitopes restricted by different HLA-A, -B, or -C alleles $(6,19,20)$. Therefore, the accurate quantification of a total HIV-specific CD8 ${ }^{+}$T-cell response will require assessment of the response to all possible epitopes, ideally covering all the epitopes that could bind patient's HLA haplotype.

The "reverse immunogenetics" approach by using the HLA peptide-binding motifs has been successful to define T-cell epitopes and to find new peptide epitopes that can be used for assessing T-cell response $(20,21)$. Interestingly, the peptide binding motifs are now available for a large number of HLA class I and class II alleles covering more than $90 \%$ of HLA haplotypes in different populations (20-22). Moreover, the variability of the virus protein sequences should also be considered in designing epitopes for assessing CTL response in HIV-infected subjects. In fact, mutations inside the epitope could either alter the binding ability to the HLA molecule, as well as the affinity for the epitope specific TCR (23).

Here we report the use of HLA-peptide binding motif to select promiscuous peptides on the most conserved areas of GAG HIV gene product for monitoring the CTL response in HIV infected subjects by using ICS tests for detecting IFN- $\gamma$ producing cells.

\section{Materials and Methods}

\section{Subjects}

A total of 17 HIV-1 infected patients were recruited in this study. Twelve patients were from the Clinical Divisions of the INMI "L. Spallanzani," Rome, Italy
(3 men, 9 women; mean age 39 years [range 26-55], all Caucasian) with a $\mathrm{CD}^{+}$cell counts of $673 / \mu \mathrm{l}$ (range 501-878) and undetectable viremia (below 80 copies/ml, branched DNA). All of these patients were undergoing HAART and were evaluated the time of enrolment and at 1 month after HAART interruption for side effects (mainly lipodystrophy). At this time, they presented a reduced $\mathrm{CD} 4^{+}$cell counts of 509/ $\mu \mathrm{l}$ (range 340-894) and an increased viremia 2896 copies/ml (range 80-670,000) (Table 1).

In contrast, five patients were from the CIRBA, Abidjan, Ivory Coast (2 men, 3 women; mean age 36 years [range 33-42], all Africans) with $\mathrm{CD}^{+}$

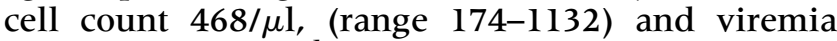
130,296 copies $\mathrm{ml}^{-1}$ (range 6162-473,480) (Table 1). One out of five patients was under HAART, while the others did not receive any treatment at the time of enrollment.

The prevalent clade of HIV-1 virus in Italy is clade B whereas in Ivory Coast is clade A/G (25).

All patients signed an informed consent as approved by the Institutional Review Board of the Institute "L. Spallanzani," Rome Italy and by the Institutional Review Board of CIRBA, Ivory Coast.

Eight buffy coats were obtained from healthy donors and used as negative controls in all assays.

\section{Sequence Analysis of Gag HIV-1 Protein and} Epitope Prediction

HIV-1 Gag protein sequences were downloaded from a GeneBank protein database. A total number of 814 protein sequences were analyzed and aligned by Antheprot software (26).

The consensus sequences of the most conserved areas were submitted for the identification of HLA peptide-binding motifs on HIV-Immunology Database (http://hiv-web.lanl.gov/immunology/) (20) for 94 HLA-class I serotypes (A1, A10, A11, A19, A2, A2.1, A23, A24, A25, A26, A28, A29, A3, A3.1, A30, A31, A32, A33, A34, A35, A36, A43, A66, A68, A69, $\mathrm{A} 74, \mathrm{~A} 9, \mathrm{~B} 12, \mathrm{~B} 13, \mathrm{~B} 14, \mathrm{~B} 15, \mathrm{~B} 16, \mathrm{~B} 17, \mathrm{~B} 18, \mathrm{~B} 22$, $\mathrm{B} 24, \mathrm{~B} 27, \mathrm{~B} 35, \mathrm{~B} 37, \mathrm{~B} 38, \mathrm{~B} 39, \mathrm{~B} 40, \mathrm{~B} 41, \mathrm{~B} 42, \mathrm{~B} 44$, $\mathrm{B} 45, \mathrm{~B} 46, \mathrm{~B} 47, \mathrm{~B} 48, \mathrm{~B} 49, \mathrm{~B} 5, \mathrm{~B} 50, \mathrm{~B} 51, \mathrm{~B} 52, \mathrm{~B} 53$, $\mathrm{B} 54, \mathrm{~B} 55, \mathrm{~B} 56, \mathrm{~B} 57, \mathrm{~B} 58, \mathrm{~B} 59, \mathrm{~B} 60$, B61, B62, В63, $\mathrm{B} 64, \mathrm{~B} 65, \mathrm{~B} 67, \mathrm{~B} 7, \mathrm{~B} 70, \mathrm{~B} 71, \mathrm{~B} 72, \mathrm{~B} 73, \mathrm{~B} 75, \mathrm{~B} 76$, B77, B78, B8, B81, Bw52, Bw57, Bw60, Bw62, C4, Cw1, Cw10, Cw2, Cw3, Cw4, Cw5, Cw6, Cw7, Cw8, Cw9), corresponding to 281 different HLA class I alleles (27). Subsequently, the areas of Gag protein identified as containing a large number of peptide binding motifs, were analyzed by the quantitative implemented HLA peptide-binding motifs databases SYFPEITHI (http://www.syfpeithi.de) (28) and BIMAS (http://bimas.dctr.nih.gov/molbio/ hla_bind/) (29) for prediction and scoring of each putative epitope for all the available HLA class I alleles in the two databases. A further analysis was made by PAProC (http://www.paproc.de) (24) to identify the most probable area of proteasome processing to properly design overlapping peptides 
Table 1. Main characteristics of HIV-infected patients enrolled in the study

\begin{tabular}{|c|c|c|c|c|c|c|c|c|c|c|c|c|}
\hline \multirow[b]{2}{*}{ Patient } & \multirow[b]{2}{*}{ Sex } & \multirow[b]{2}{*}{ Age } & \multirow[b]{2}{*}{ Race } & \multirow[b]{2}{*}{ HAART } & \multicolumn{4}{|c|}{ At Enrollment } & \multicolumn{4}{|c|}{1 Month After HAART Interruption } \\
\hline & & & & & $\begin{array}{c}\text { CD4 } \\
(\mathrm{N} / \mu \mathrm{l})\end{array}$ & $\begin{array}{c}\text { CD8 } \\
(\mathrm{N} / \mu \mathrm{l})\end{array}$ & $\begin{array}{l}\text { Viral Load } \\
\text { (copies/ml) }\end{array}$ & $\begin{array}{c}\text { Anti-GAG } \\
\text { Peptides CTL } \\
\text { (N precursors } / \mathrm{ml} \text { ) }\end{array}$ & $\begin{array}{c}\text { CD4 } \\
(\mathrm{N} / \mu \mathrm{l})\end{array}$ & $\begin{array}{c}\text { CD8 } \\
(\mathrm{N} / \mu \mathrm{l})\end{array}$ & $\begin{array}{l}\text { Viral Load } \\
\text { (copies/ml) }\end{array}$ & $\begin{array}{c}\text { Anti-GAG } \\
\text { Peptides CTL } \\
\text { (N precursors } / \mathrm{ml} \text { ) }\end{array}$ \\
\hline $\mathrm{COl}$ & $\mathrm{F}$ & 37 & Caucasian & Yes & 878 & 1153 & $<50$ & 922 & 644 & 1342 & 2900 & 805 \\
\hline $\mathrm{C} 03$ & $\mathrm{~F}$ & 36 & Caucasian & Yes & 795 & 559 & $<50$ & 727 & 678 & 1724 & 170000 & 7068 \\
\hline $\mathrm{C} 04$ & M & 47 & Caucasian & Yes & 788 & 1508 & $<50$ & 452 & 347 & 2597 & 670000 & 2619 \\
\hline $\mathrm{C} 05$ & $\mathrm{~F}$ & 26 & Caucasian & Yes & 759 & 1427 & $<50$ & 3710 & 894 & 1995 & 300 & 7182 \\
\hline $\mathrm{C} 08$ & $\mathrm{~F}$ & 50 & Caucasian & Yes & 501 & 1446 & $<50$ & 864 & 340 & 2726 & 71000 & 6815 \\
\hline $\mathrm{C} 10$ & $\mathrm{~F}$ & 40 & Caucasian & Yes & 502 & 651 & $<50$ & 391 & 509 & 956 & 80 & 383 \\
\hline Cll & $\mathrm{F}$ & 38 & Caucasian & Yes & 512 & 435 & $<50$ & 391 & 401 & 1505 & 85000 & 4214 \\
\hline $\mathrm{C} 13$ & $\mathrm{~F}$ & 31 & Caucasian & Yes & 625 & 623 & $<50$ & 141 & 493 & 705 & 42000 & 187 \\
\hline $\mathrm{C} 15$ & $\mathrm{~F}$ & 30 & Caucasian & Yes & 622 & 870 & $<50$ & 87 & 426 & 1683 & 10000 & 505 \\
\hline $\mathrm{C} 16$ & $\mathrm{~F}$ & 34 & Caucasian & Yes & 601 & 948 & $<50$ & 15831 & 471 & 701 & 19000 & 2804 \\
\hline $\mathrm{C} 18$ & M & 55 & Caucasian & Yes & 632 & 1392 & $<50$ & 417 & 522 & 1508 & 57000 & 151 \\
\hline $\mathrm{C} 29$ & $\mathbf{M}$ & 47 & Caucasian & Yes & 862 & 1425 & $<50$ & 1567 & 382 & 1444 & 770 & 2021 \\
\hline A66 & $\mathrm{F}$ & 35 & African & Naive & 1132 & 907 & 11027 & 1451 & n.a.* & n.a. & n.a. & n.a. \\
\hline A67 & M & 36 & African & Naive & 511 & 1142 & 11230 & 1028 & n.a. & n.a. & n.a. & n.a. \\
\hline A68 & $\mathrm{F}$ & 34 & African & Yes & 535 & 2153 & 6162 & 3229 & n.a. & n.a. & n.a. & n.a. \\
\hline A69 & $\mathrm{F}$ & 33 & African & Naive & 186 & 1458 & 473480 & 728 & n.a. & n.a. & n.a. & n.a. \\
\hline A70 & M & 42 & African & Naive & 174 & 1258 & 149548 & 1887 & n.a. & n.a. & n.a. & n.a. \\
\hline
\end{tabular}

*n.a., not applicable.

containing more than one binding profile. At the end of analysis each selected 15-mer contained one or more epitopes putatively able to bind, with a minimum of $30 \%$ of the maximum binding of any allele belong to a HLA-class I serologic specificity, at least two different HLA serologic specificities for each HLA class I locus (A, B, or C) and recognized by HLA class I gene products from two different loci.

\section{Peptides and Protein}

Peptides of 15 amino acids in length were used including selected regions from the HIV-1 Gag protein. The peptides were purchased from Sigma-Genosys (Cambridge, UK) as free amino acids. All synthetic peptides were purified by reverse-phase chromatography (RPC) $>90 \%$ purity. Sequence and purity were confirmed by mass spectrometry and analytical RPC.

Lyophilized peptides were resuspended in DMSO at stock concentrations of $10 \mathrm{mg} / \mathrm{ml}$ for each peptide. Peptide mixes contained an equi-concentration of all the 28 peptides.

Purified Gag protein $(100 \mu \mathrm{g} / \mathrm{ml})$ was obtained by Protein Science (Meriden, CT, USA) and was used at final concentration of $3 \mu \mathrm{g} / \mathrm{ml}$.

\section{Antibodies}

Unconjugated mouse-anti-human CD28 (IgGl, clone CD28.2); unconjugated mouse-anti-human CD49d
(IgGl, clone 9F10); fluorescein (FITC)-conjugated mouse-anti-human IFN (IgGl, clone B27); PEcyanine-5 (Cy-5)-conjugated mouse-anti-human CD3 (IgG1, clone RPA-T3); AlloPhycoCyanin (APhC)-conjugated mouse-anti-human CD8 (IgGl, clone RPA-T8) monoclonal antibodies, and FITCconjugated IgGl isotype-matched control (IgGl clone MOPC-21) were obtained from Becton Dickinson Immunocytometry Systems (San Jose, CA, USA).

\section{Cell Stimulation}

Peripheral blood mononuclear cells (PBMC) were obtained using standard Ficoll-Hypaque (Pharmacia, Uppsala, Sweden) density centrifugation. Stimulation was performed as already described with minor modifications $(13,17)$. Fresh or live thawed PBMC $\left(1 \times 10^{6}\right)$ in $1 \mathrm{ml}$ of complete RPMI 1640, $10 \% \mathrm{v} / \mathrm{v}$ heat-inactivated FCS, $2 \mathrm{mM}$ L-Glutamine, $10 \mathrm{U} / \mathrm{ml}$ penicillin/streptomycin, were incubated with $1 \mu \mathrm{g}$ each of anti-CD28 and CD49d monoclonal antibodies and $1 \mu \mathrm{g}$ mix of GAG peptides and $3 \mu \mathrm{g}$ of GAG protein. To control the spontaneous cytokine production, cells incubated with only anti-CD28 and -CD49d were included in each experiment. The IFN- $\gamma$ release induced by PMA $(50 \mathrm{ng} / \mathrm{ml})$ plus ionomycin $(10 \mu \mathrm{g} / \mathrm{ml})$ was used as a positive control. The cultures were incubated at $37^{\circ} \mathrm{C}$ in a $5 \% \mathrm{CO}_{2}$ incubator for $\mathrm{l} \mathrm{hr}$, followed by additional $5 \mathrm{hr}$ 
incubation with $10 \mu \mathrm{g} / \mathrm{ml}$ of the secretion inhibitor Brefeldin-A (Sigma, St. Louis, MO, USA).

\section{Immunofluorescent Staining}

Peptide-stimulated and control cultures were washed in cold Dulbecco's phosphate-buffered saline (dPBS) containing $1 \%$ BSA and $0.1 \%$ sodium azide. Cells were washed twice in PBS, $1 \%$ BSA, and $0.1 \%$ sodium azide and stained with monoclonal antibodies specific for the membrane antigens described above for $15 \mathrm{~min}$ a $4^{\circ} \mathrm{C}$. Samples were then fixed in $1 \%$ paraformaldehyde for $10 \mathrm{~min}$ at $4^{\circ} \mathrm{C}$, incubated with anti-interferon (IFN)- $\gamma$ monoclonal antibody diluted in PBS 1X, BSA $1 \%$, and saponin $0.5 \%$. The cells were finally washed twice in PBS 1X, BSA $1 \%, 0.1 \%$ saponin, and resuspended in FACS FLOW before acquiring on FACScalibur (Becton Dickinson). Control for nonspecific staining was monitored with isotype-matched monoclonal antibody and nonspecific staining was always subtracted from specific results.

Flow Cytometric Analysis

Six-parameter flow cytometric analysis was performed on a FACScalibur flow cytometer (Becton Dickinson Immunocytometry Systems), using FITC, PECy-5, and APhC as the fluorescent parameters. At least 100,000 live events were acquired, gated on small viable lymphocytes. Data files were analyzed using CellQuest software (Becton Dickinson).

\section{Statistical Analysis}

Demographic data are presented as means \pm standard deviations (SD) of the mean. Comparisons among groups were performed by using the Wilcoxon and Fisher test, as appropriate. A positive cut-off value of 50 IFN- $\gamma$ GAG-specific CD 8 cells $/ \mathrm{ml}$ was established on the mean +3 SD of the test results of the eight buffy coats obtained from HIVnegative healthy donors.

\section{Results}

\section{Selection of Promiscuous HIV-Gag Epitopes}

A consensus sequence of HIV-1 GAG protein was obtained by CLUSTALW alignment using Antheprot software from 784 full-length GAG sequences of HIV-1 presents in the GeneBank protein database (Fig. 1). The most conserved areas of the protein, mainly related to the p17 and p24 products of the full-length GAG precursor, were then screened for the presence of HLA class I peptide-binding motifs by using the Epitope motif search facility at the HIVImmunology Database covering 94 HLA-class I serotypes (see Methods section for the list of serotypes included in the screening), corresponding to 281 different HLA class I alleles. The five most conserved areas were identified as containing a higher number of HLA class I epitopes covering less than one-third of the overall Gag protein sequences. Two of these corresponded to the pl7 (amino acids 19-53 and 66-89 of the consensus sequences) and three to the p24 (amino acid 150-180 and 181-200 of the consensus sequences) GAG product (Fig. 1).

These selected areas were then analyzed for scoring each putative epitope by quantitative implemented

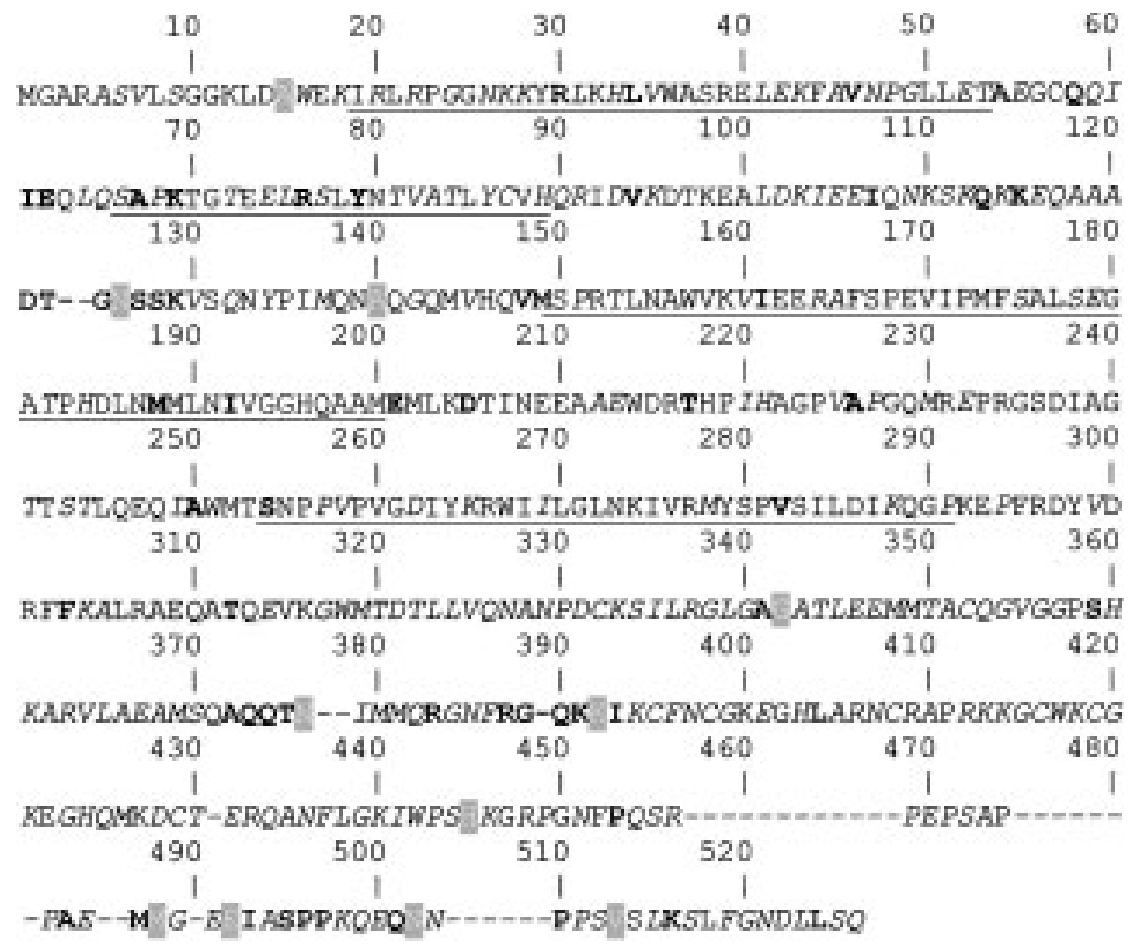

Fig. 1. Consensus sequence alignment and CTL epitope prediction of GAG protein. GAG protein sequences deposited in GeneBank were aligned and consensus analyzed for the presence of HLA class I peptide-binding motifs by using the Epitope motif search facility at the HIV-Immunology Database. Amino acids with $100 \%$ identity were depicted as normal character, amino acid with $>75 \%$ identity were reported in italics, amino acids with $>50 \%$ identity were reported in bold, and amino acids with $<50 \%$ identity were highlighted in grey. Gaps in the sequence represent amino acids of GAG protein present in less than $10 \%$ of the deposited sequences. Promiscuous HLAclass I epitope areas were underlined. 
HLA binding motif databases SYFTHPEY and BIMAS. Moreover, to take into account any possible contribution of the HIV-1 virus variability, the analysis was extended to every consensus sequences including all of the amino acid changes reported in the selected areas (all with $>50 \%$ identity, see Fig. 1). Finally, to design properly overlapping peptides for areas containing more than one epitope binding profile, the consensus sequence was analyzed by PAProC identifying the putative positions of proteasome cleavage along the GAG sequence.

At the end of analysis 28 different 15-mers spanning the 5 selected areas were designed (Table 2 ). Each selected peptide contained (1) epitopes with a binding score higher than $30 \%$ of the maximum admitted for the listed serotype for (2) at least two different HLA-serotypes of any HLA-class I locus on (3) at least two different HLA-class I loci (Table 2). The HLA specificities evaluated for scoring the epitopes were able to cover more than $90 \%$ of the different HLA class I haplotypes in different human populations (data from XII IHW; Table 3).

The HIV-1 variability of each designed peptide was evaluated by adding all of the mutant positions with respect to the designed peptide found by the Epitope Aligner on the 122 HIV-1 Gag sequences of the HIV-Immunology Database. All of the peptides presented variability from $1.2-20.5 \%$ (Fig. 2). However, because eight peptides represented a point-mutated form of other peptides (see Fig. 2, peptides: 1.2a and $1.2 \mathrm{~b}, 1.3 \mathrm{a}$ and $1.3 \mathrm{~b}, 1.5 \mathrm{a}$ and $1.5 \mathrm{~b}, 2.1 \mathrm{a}$ and $2.1 \mathrm{~b}, 2.3 \mathrm{a}$ and $2.3 \mathrm{~b}, 4.1 \mathrm{a}$ and $4.1 \mathrm{~b}, 5.4 \mathrm{a}$ and $5.4 \mathrm{~b}, 5.5 \mathrm{a}$ and $5.5 \mathrm{~b}$ ) that took into account critical changes in HIV-1 variability in areas that could be responsible for the interaction between the HLA class I/peptide complex and TCR interaction, the overall variability when these peptides were evaluated together was less than $\mathbf{9 \%}$ (Fig. 2, insert).

\section{Analysis of IFN- $\gamma$ Release of $\mathrm{CDB}^{+} \mathrm{T}$ Cells in Response to the Selected Epitopes in Different Populations}

The selected 28 peptides were then used in a pool for assessing the IFN- $\gamma$ release in $\mathrm{CD}^{+} \mathrm{T}$ cells by ICS in fresh and frozen PBMCs of HIV-1 infected patients in comparison to recombinant GAG protein. The IFN- $\gamma$ release of $\mathrm{CD}^{+} \mathrm{T}$ cells in response to the GAG protein was significantly reduced in frozen compared to fresh PBMCs, while the pool of GAG peptides was able to induce a HIV-1 specific CD8response in fresh as well in frozen cells (Fig. 3A).

Subsequently, the GAG peptide pool was used to assess the IFN- $\gamma$ release in $\mathrm{CD}^{+}{ }^{+} \mathrm{T}$ cells in HIV1-infected subjects with different viral loads, in different ethnic populations from geographical areas with a different HIV clade prevalence on cell bank samples.

Twelve Caucasian subjects were evaluated at enrolment of the study when they were under effective HAART (with a viral load $<50$ copies, branched DNA). At this time point, by using the GAG peptide pool as stimulus, we were able to detect a significantly higher response $(2125 \pm 4426$ IFN- $\gamma$-specific CD8 cells/ml, $p<0.05$ versus HIV-negative controls, Table 1) in comparison to HIV-seronegative controls (Fig. 3B). In contrast, in the same cell bank samples the response to recombinant GAG proteins was present in only 3 out of 12 subjects $(p<0.001$ versus peptide pool, Fisher's exact test; Fig. 3B).

These 12 Caucasian HIV-positive patients were also evaluated 1 month after HAART interruption. At this time point, a viral rebound was observed $(94,004 \pm 188,175$ copies branched DNA, $p<0.001$ respect to enrolment; Table 1) together with a reduction of CD4 cells counts $(509 \pm 161 / \mu \mathrm{l}, p<0.05$ respect to enrolment; Table 1) and an increase of CD8 cells counts ( $1574 \pm 644 / \mu \mathrm{l}, p<0.05$ respect to enrolment; Table 1). By using the GAG peptide pool as stimulus, a significantly higher anti-HIV-specific $\mathrm{CD}^{+}$response was detected $(2896 \pm 2780$ IFN$\gamma$-specific CD8 cells/ml, $p<0.05$ versus enrolment; Table 1), confirming that the enumeration of IFN- $\gamma$ cells by ICS should be useful for monitoring the anti-HIV-specific CD8 response $(1,6,7)$. The response against recombinant GAG protein was present only in 2 out of the 12 patients after HAART interruption $(p<0.001$ versus peptide pool, Fisher's exact test; Fig. 3B).

The ability of the GAG peptide pool to detect anti-HIV-specific CD8 response independently of the HIV-clade and HLA variability was assessed in five HIV-1-infected African subjects enrolled in a country with different HIV-1 clade prevalence. All HIV-infected African patients present a high frequency of GAG specific $\mathrm{CD}^{+}$T-cells producing IFN- $\gamma(1665 \pm 978$ IFN- $\gamma$ specific CD8 cells/ml, $p<0.05$ versus controls), however not different to HIV-1-infected Caucasian individuals $(p>0.05$ versus HIV-1-infect Caucasians) (Table 1). Thus, this pool of HLA-class I promiscuous HIV-1 clade independent peptides may allow one to perform cohort studies of HIV-specific CTL response on biological bank samples.

\section{Discussion}

HIV-specific CTLs play a key role in controlling HIV infection (1). Accurate monitoring of these cells could represent an important tool for determining the effects of HIV therapy $(1,6,7,13)$. However, some limitations in the use of tests for determining the amount of the HIV-1-specific CTL in the daily clinical management of HIV-infected subjects are represented by the HLA patients' restriction and the interand intraclade variability of the HIV-1 virus (18).

In this study, we confirmed the utility of ICS assay for assessing cytokine production to measure HIVspecific $\mathrm{CD}^{+}{ }^{\mathrm{T}}$-cell responses. Moreover, we showed that this assay could be used for HIV immunodiagnosis using a pool of HLA-class I promiscuous and HIVclade-independent peptides. This method may allow 


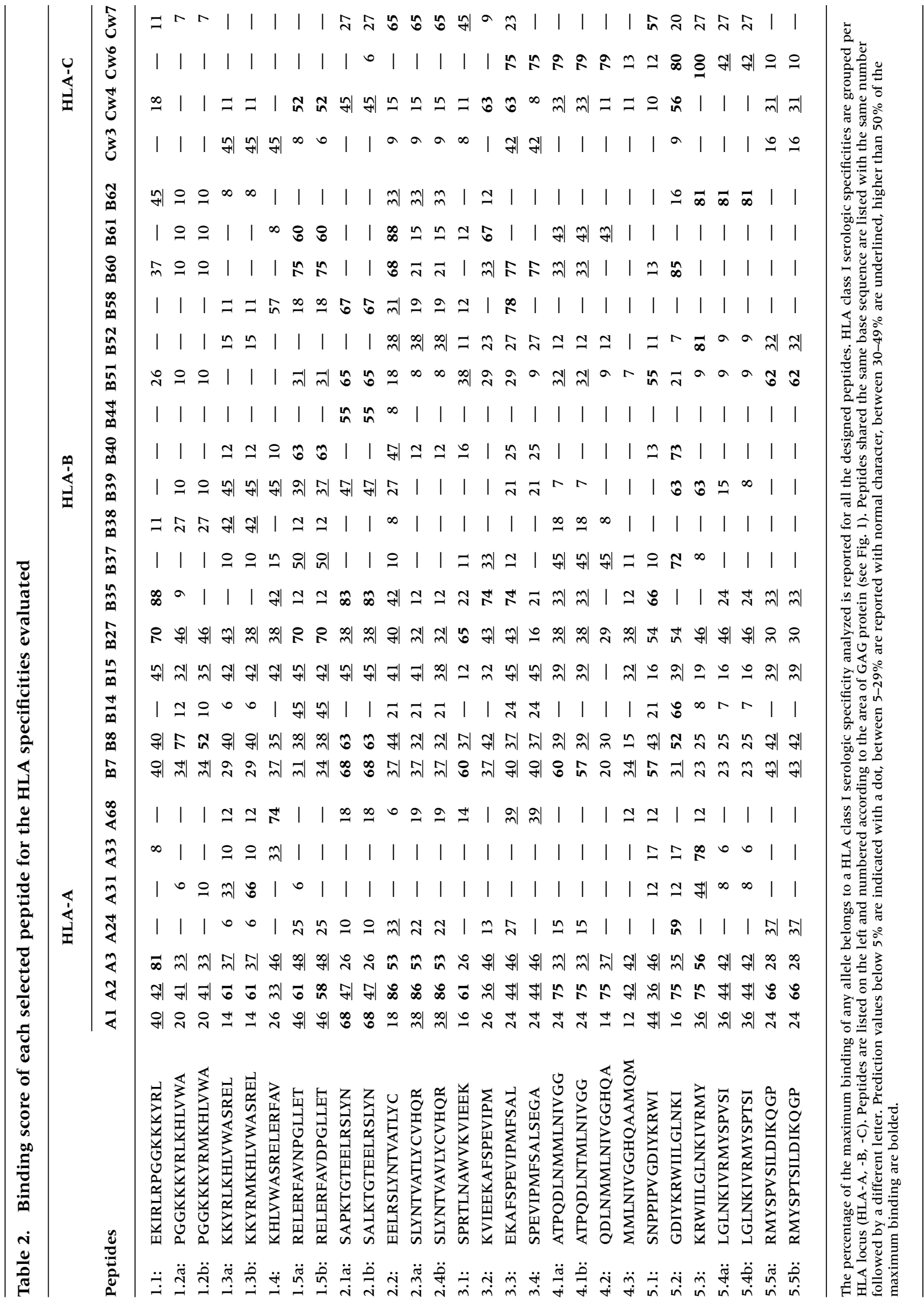


Table 3. Frequencies of the HLA class I specificities analyzed in selecting the putative CTL epitopes in the Gag protein (data from XII IHW)

\begin{tabular}{|c|c|c|c|c|c|}
\hline \multirow[b]{2}{*}{ HLA Specificity* } & \multicolumn{5}{|c|}{ Populations } \\
\hline & Caucasian & North African & African & Asian & Amerind \\
\hline Al & 14.3 & 3.6 & 4.7 & 2.2 & 4.2 \\
\hline $\mathrm{A} 2$ & 27.8 & 13.6 & 16.9 & 25.1 & 31.5 \\
\hline A3 & 12.6 & 5.9 & 6.1 & 1.1 & 2.6 \\
\hline A24 & 8.9 & 5.4 & 3.4 & 24.3 & 18.0 \\
\hline A31 & 2.5 & 0.8 & 2.6 & 5.1 & 24.2 \\
\hline A33 & 1.7 & 8.0 & 8.2 & 7.8 & 5.1 \\
\hline A68 & 4.1 & 2.4 & 8.1 & 1.2 & 0 \\
\hline B7 & 9.2 & 4.2 & 7.4 & 8.6 & 2.7 \\
\hline B8 & 8.7 & 3.4 & 4.9 & 0.1 & 2.6 \\
\hline B 14 & 3.7 & 3.6 & 2.8 & 0.4 & 3.2 \\
\hline B 15 & 3.3 & 5.2 & 9.3 & 10.2 & 10.8 \\
\hline B27 & 3.8 & 1.7 & 1.2 & 1.8 & 1.0 \\
\hline B35 & 9.7 & 4.8 & 8.9 & 6.5 & 25.8 \\
\hline B37 & 1.4 & 0.8 & 0.7 & 0.7 & 0 \\
\hline B38 & 2.8 & 0.8 & 0.2 & 2.2 & 2.1 \\
\hline B39 & 1.9 & 4.5 & 1.2 & 3.6 & 17.9 \\
\hline B40 & 0.8 & 1.2 & 0.3 & 6.3 & 12 \\
\hline B44 & 12.1 & 5.1 & 5.8 & 5.4 & 2.2 \\
\hline B51 & 6.5 & 2.5 & 2.8 & 5.3 & 9.5 \\
\hline B52 & 1.6 & 2.5 & 2.7 & 5.8 & 2.4 \\
\hline B58 & 1.5 & 6.3 & 8.5 & 1.8 & 0.2 \\
\hline B60 & 3.4 & 0 & 0.4 & 4.4 & 1.5 \\
\hline B61 & 1.6 & 0.8 & 0.3 & 6.2 & 8.0 \\
\hline B62 & 4.7 & 1.8 & 0.8 & 9.2 & 5.3 \\
\hline Cw3 & 6.3 & 2.8 & 1.3 & 12.2 & 1.1 \\
\hline Cw4 & 12.3 & 11.8 & 16.5 & 5.7 & 18.9 \\
\hline Cw6 & 9.0 & 8.0 & 10.5 & 3.9 & 4.6 \\
\hline Cw7 & 23.3 & 13.7 & 17.4 & 17.0 & 30.6 \\
\hline $\begin{array}{l}\text { Overall } \\
\text { Specificity }^{\dagger}\end{array}$ & $96 \%$ & $91 \%$ & $93 \%$ & $95 \%$ & $98 \%$ \\
\hline
\end{tabular}

*Data summarize the frequencies of the HLA class I alleles included in the serologic specificities reported and used for analyzing the putative CTL epitopes of GAG protein.

${ }^{\dagger}$ Overall frequency of the HLA class I haplotypes in the different populations including the serologic specificities analyzed.

for the rapid characterization and quantification of the specific CTL response in any HIV-infected patient, independently of their HLA haplotype and can be used on both fresh and cryopreserved PBMC samples, as already reported when using single or pool of peptides as antigens $(13,17)$.

An important aspect in setting a diagnostic assay is to use a rapid and easily automated system working on virtually all of the subjects who carry the disease. In this context, ICS staining for assessing the specific CTLs has been shown to present several advantages in comparison to other techniques such as tetramer staining and ELISpot. In fact, ICS allows for testing multiple peptides at a single time and provides at the same time quan- titative and phenotypic assessment of $\mathrm{CD}^{+} \mathrm{T}$ responding cells (12-16). Moreover, the technique could be easily automated and made routine by using analytical instruments already available in most clinical laboratories that perform flowcytometric analysis. In comparison with other analytical systems for assessing CTL response, this is economically advantageous.

As a target for assessing the anti-HIV-specific CTL response, we used the GAG protein because it reassembled some important characteristics for setting a diagnostic test. First, CTL response to GAG derived peptides and GAG protein are commonly found in most HIV-infected patients (13-17). Second, the GAG protein is one of the most conserved 


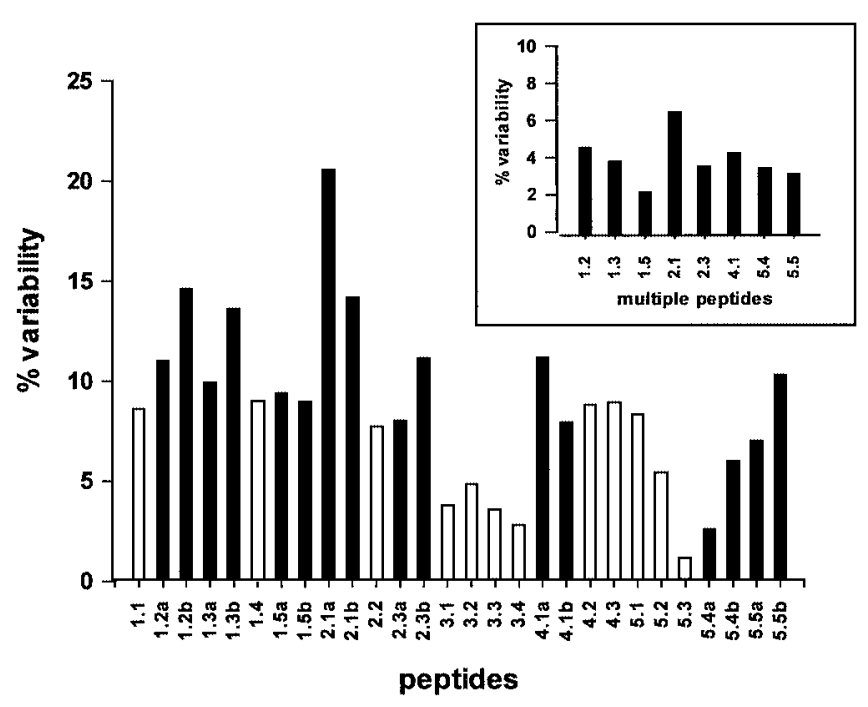

Fig. 2. Analysis of the HIV-1 interstrain variability of each designed peptide sequence. The percentage of interstrain variability (on the ordinate) is reported for each single peptide sequence. Peptides sharing the same based sequence, in order to take into account critical changes in HIV-1 variability are reported as closed bars. Peptides in which sequences are represented only once are depicted as open bars. Inset: the overall variability of the peptides sharing the same base sequence is reported.

HIV-1 gene products (25) allowing for the selection of a few specific regions representative of almost all HIV-1 clades, circumventing the problem of HIV-1 virus variability. Goulder et al. (30) have shown that two-thirds of the response against GAG epitopes recognized by HIV-1 clade $-\mathrm{B}$ and $-\mathrm{C}$ infected subjects is located in 3 out of 46 peptides spanning the p17 and p24 sequences, irrespective of the clade and ethnicity. However, there were distinctive differences between the dominant responses made by Caucasians and Africans. Interestingly, the areas covered by the three peptides identified in Goulder's study are included in our pool of HLA class I promiscuous and HIV-clade-independent GAG peptides. Moreover, as demonstrated by Betts et al. (13) by using ICS associated with pool matrix peptide analysis of 95 optimal GAG, POL, ENV, and NEF CTL-peptide epitopes of the HIV immunology database (20), the individual's overall CTL response to HIV is inadequately represented by the response to a single or few epitopes. An accurate quantification of the total HIV-specific CD8-response will require assessment of the response to all possible epitopes. In fact, although some patients sharing HLA alleles occasionally recognize common peptides, the response is rarely concentrated on a few dominant epitopes in the same group of patients (17).

The advantages of using ICS and GAG as targets for assessing the HIV-specific CTL response was associated with the computer-based selection of peptide epitopes putatively able to bind to more than $90 \%$ of the HLA class I haplotypes in different
A

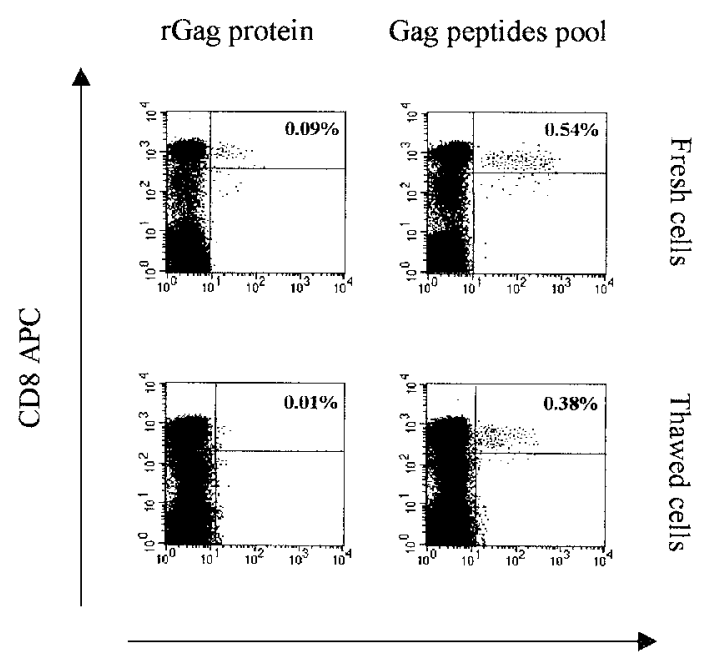

IFN- $\gamma$ FITC

B

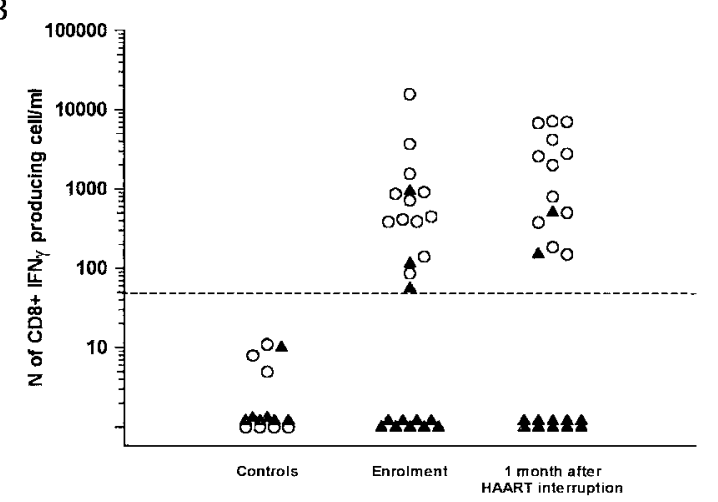

Fig. 3. (A) Use of the selected GAG-derived peptides and GAG protein for the identification of IFN-g producing CD8specific $T$ cells in fresh and frozen PBMCs of HIVinfected subjects. Fresh (upper panels) and frozen (lower panels) PBMCs of an HIV-1-infected subject were stimulated with recombinant GAG protein (left panels) or the pool of the selected GAG-derived peptides (right panels) as described in Materials and Methods. Each cytofluorimetric panel shows the $\mathrm{CD}^{+}$cells (on the ordinate) producing IFN- $\gamma$ (on the abscissa). The frequency of IFN- $\gamma / \mathrm{CD} 8^{+}$cells over the total of $\mathrm{CD}^{+}$lymphocytes for each cytofluorimetric panel is reported. One of three independent experiments is shown. (B) Quantification of the CTL response against recombinant GAG protein (solid triangles) and the pool of selected GAG-derived peptides (open circles) in cell bank samples of Caucasian HIV-1-infected subjects at the time of their enrolment in the study and one month after interruption of HAART and in HIV-negative healthy controls. The number of $\mathrm{CD}^{+}$IFN- $\gamma$-producing cells $/ \mathrm{ml}$ of blood is reported on the ordinate. Positive cut-off value of 50 IFN- $\gamma$ Gagspecific CD8 cells/ml established on the mean +3 SD of the negative control sample test results is reported as a dashed line.

populations and designed to take into account the natural process with which an endogenous protein is processed by proteasome $(21,22,24)$. Interestingly, all of the HLA class I promiscuous GAG-epitope peptides identified in this study have already been identified as epitopes able to bind to one or more HLA molecules (see Brander and Goulder [20] for a 
review). By using a computer-assisted selection of the HLA class I epitopes, one of the greatest advantages is that a reduced number of peptides able to cover almost all of the HLA specificities can be used instead of overlapping peptides spanning all of the protein sequences for setting a CTL assay. In the design of a CTL assay for HIV immunodiagnosis, considering the possible variability in the individual's CTL response, we selected 20 different 15-mer, with eight multiple sequences for HIV-1 variability, that are representative of the response against GAG protein in all HIV-1-infected subjects that we tested independently of their HLA haplotype and HIV-1 virus clade. Therefore, the selected peptides that we used are considerably less than approximately 100 overlapping 15-mer that have been used for covering the most relevant GAG protein sequences. Moreover, our peptide mix is different from the 37 optimal GAG peptides reported in the HIV immunology database that have previously been used $(13,17)$ and of the 187 GAG epitopes reported in the database itself (20).

The fine assessment of the $\mathrm{CD} 8^{+} \mathrm{T}$ cells response during HIV infection should represent an important goal for monitoring HIV-infected patients during different stages of infection. In fact, it is well known that CD8 $\mathrm{T}$ cells play a critical role in the control of HIV infection (1). Specifically, the appearance of HIV-specific $\mathrm{CD}^{+}{ }^{+} \mathrm{T}$ cells is closely associated with the drop in viremia $(1,31)$ and that HIV-infected subjects who do not efficiently control the virus during their primary infection have been associated with rapid progression to AIDS (1). Moreover, $\mathrm{CD}^{+} \mathrm{T}$ cells select viral escape mutations, suggesting that they exert considerable selective pressure on the virus (2-5). During HAART, the anti-HIV specific CD8 response is reduced and increased by therapy interruption as reported in this study and by others $(6,7)$. Finally, in AIDS patients, when the immune system is dramatically compromised, in the presence of a very high viral load the anti HIV-specific CTL response is significantly reduced (1). Thus, the routine analysis of the CTL response evocated during HIV infection may represent an important tool to monitor the immune status of the HIV infected patients for identifying anti-HIV-specific CTL response in healthy (HIV-negative) contacts of HIVinfected subjects (8-10) or in subjects undergoing HIV-1 vaccine trials.

In conclusion, we demonstrated the efficacy of computer-assisted predictions in defining the physiologically relevant or immunodominant epitopes independently of the HIV-1 variability and major histocompatibility complex diversity. This approach, combined with the rapid and sensitive evaluation by ICS assays for measuring CTL response, may represent an important tool both for diagnostic purposes and vaccine design. The HIV-1 GAG CTL assay described in this study has a broad specificity and is rapid, sensitive, and inexpensive. This technology could be transferred to other infectious diseases where monitoring or boosting CTL responses could be clinically relevant.

\section{Acknowledgments}

We thank Mr. Mauro Brescia for technical assistance, Dr Delia Goletti and Dr Federico Martini (I.N.M.I., "L. Spallanzani" IRCCS, Rome, Italy) for the continuous and helpful discussions and the critical reading of the manuscript, Dr Henry Chenal (clinical director of CIRBA) for his helpful advise in the recruitment and characterization of patients in Abidjan and Zana Mariano for editing the manuscript.

This study has been supported by grants from the "Ministero della Salute", "Istituto Superiore della Sanità" (grant $n^{\circ} 30 \mathrm{C} 23$ and 45D/1.21) and "UNESCO-CNR" 1999-2001.

\section{References}

1. McMichael AJ, Rowland-Jones SL. (2001) Cellular immune response to HIV. Nature 410: 980-987.

2. Phillips RE, Rowland-Jones S, Nixon DF, et al. (1991) Human immunodeficiency virus genetic variation that can escape cytotoxic T cell recognition. Nature 354: 453-459.

3. Borrow P, Lewicki H, Wei X, et al. (1997) Antiviral pressure exerted by HIV-1-specific cytotoxic T lymphocytes (CTLs) during primary infection demonstrated by rapid selection of CTL escape virus. Nat. Med. 3: 205-211.

4. Evans DT, O'Connor DH, Jing P, et al. (1999) Virus-specific cytotoxic T-lymphocyte responses select for amino-acid variation in simian immunodeficiency virus Env and Nef. Nat. Med. 5: 1270-1276.

5. Goulder PJR, Phillips RE, Colbert RA, et al. (1997) Late escape from an immunodominant cytotoxic T-lymphocyte response associated with progression to AIDS. Nat. Med. 3: 212-217.

6. Casazza JP, Betts MR, Picker LJ, Koup RA. (2001) Decay kinetics of human immunodeficiency virus-specific CD8 $+\mathrm{T}$ cells in peripheral blood after initiation of highly active antiretroviral therapy. J. Virol. 75: 6508-6516.

7. Ortiz GM, Wellons M, Brancato J, et al. (2001) Structured antiretroviral treatment interruptions in chronically HIVl-infected subjects. Proc. Natl. Acad. Sci. U. S. A. 98: 13288-13293.

8. Kaul R, Plummer FA, Kimani J, et al. (2000) HIV-1-specific mucosal $\mathrm{CD} 8+$ lymphocyte responses in the cervix of HIV-1-resistant prostitutes in Nairobi. J. Immunol. 164: 1602-1611.

9. Kaul R, Dong T, Plummer FA, et al. (2001) CD8+ lymphocytes respond to different HIV epitopes in seronegative and infected subjects. J. Clin. Invest. 107: 1303-1310.

10. Rowland-Jones SL, Dong T, Fowke KR, et al. (1998) Cytotoxic $\mathrm{T}$ cell responses to multiple conserved HIV epitopes in HIVresistant prostitutes in Nairobi. J. Clin. Invest. 102: 1758-1765.

11. Koup RA, Pikora CA, Luzuriaga K, et al. (1991) Limiting dilution analysis of cytotoxic $\mathrm{T}$ lymphocytes to human immunodeficiency virus gag antigens in infected persons: in vitro quantitation of effector cell populations with p17 and p24 specificities. J. Exp. Med. 174: 1593-1600.

12. Pitcher CJ, Quittner C, Peterson DM, et al. (1999) HIV-1specific CD4+ $\mathrm{T}$ cells are detectable in most individuals with active HIV-1 infection, but decline with prolonged viral suppression. Nat. Med. 5: 518-525.

13. Betts MR, Casazza JP, Patterson BA, et al. (2000) Putative immunodominant Human Immunodeficiency Virus-specific CD8 + T-cell responses cannot be predicted by Major Histocompatibility Complex class I haplotype. J. Virol. 74: 9144-9151.

14. Gea-Banacloche JC, Migueles SA, Martino L, et al. (2000) Maintenance of large numbers of virus-specific CD8+ T cells 
in HIV-infected progressors and long-term nonprogressors. J. Immunol. 165: 1082-1092.

15. Mollet L, Li TS, Samri A, et al. (2000) Dynamics of HIV-specific CD8 + T lymphocytes with changes in viral load. The RESTIM and COMET Study Groups. J. Immunol. 165: 1692-1704.

16. Goulder PJR, Tang Y, Brander C, et al. (2000) Functionally inert HIV-specific cytotoxic T lymphocytes do not play a major role in chronically infected adults and children. J. Exp. Med. 192: 1819-1832.

17. Betts MR, Casazza JP, Koup RA. (2001) Monitoring HIV-specific $\mathrm{CD} 8+\mathrm{T}$ cell response by intracellular cytokine production. Immunol. Lett. 79: 117-125.

18. Walker BD, Korber BT. (2001) Immune control of HIV: the obstacles of HLA and viral diversity. Nat. Immunol. 2: 473-475.

19. Gray C, Lawrence J, Schapiro JM, et al. (1999) Frequency of class I restricted anti-HIV CD8 T cells in individuals receiving highly active antiretroviral therapy. J. Immunol. 162: 1780- 1788.

20. Brander C, Goulder PJR. (2000) The evolving field of HIV CTL epitope mapping: New approaches to the identification of novel epitopes. In Korber BTM, Brander C, Haynes B (eds). HIV Molecular Immunology Database. Los Alamos, NM: Los Alamos National Laboratory; pp. I1-I3.

21. De Groot AS, Bosma A, Chinai N, et al. (2001) From genome to vaccine: in silico predictions, ex vivo verification. Vaccine 19: 4385-4395.

22. Singh H, Raghava GPS. (2001) ProPred: Prediction of HLADR binding sites. Bioinformatics 17: 1236-1237.

23. Chen L. (1999) Mimotopes of cytolytic T lymphocytes in cancer immunotherapy. Curr. Opin. Immunol. 11: 219-222.

24. Nussbaum AK, Kuttler C, Hadeler KP, et al. (2001) PAProC: a Prediction Algorithm for Proteasomal Cleavages available on the WWW. Immunogenetics 53: 87-94.
25. Peeters M. (2000) Recombinant HIV sequences: their role in global epidemic. In Kuiken C, Foley B, Hahn B (eds). HIV Sequence Compendium. Los Alamos, NM: Los Alamos National Laboratory; pp. 54-72.

26. Deleage G, Combet C, Blanchet C, Geourjon C. (2001) ANTHEPROT: an integrated protein sequence analysis software with client/server capabilities. Comput. Biol. Med. 31: 259-267.

27. Schreuder GMT, Hurley CK, Marsh SGE, et al. (1999) The HLA dictionary 1999: a summary of HLA-A, -B, -C, -DRB1/3/4/5, -DQB 1 alleles and their association with serologically defined HLA-A, -B, -C, -DR and -DQ antigens. Tissue Antigens 54: 409-437.

28. Rammensee HS, Bachmann J, Emmerich NN, et al. (1999) SYFPEITHI: database for MHC ligands and peptide motifs. Immunogenetics 50: 213-219

29. Parker KC, Bednarek MA, Coligan JE. (1994) Scheme for ranking potential HLA-A2 binding peptides based on independent binding of individual peptide side-chains. J. Immunol. 152: 163-175.

30. Goulder PJR, Brander C, Annamalai K, et al. (2000) Differential narrow focusing of immunodominant Human Immunodeficiency Virus Gag-specific cytotoxic T-lymphocyte response in infected African and Caucasoid adults and children. J. Virol. 74: 5679-5690.

31. Koup RA, Hesselton RM, Safrit JT, et al. (1994) Quantitative assessment of human immunodeficiency virus type 1 replication in human xenografts of acutely infected Hu-PBL-SCID mice. AIDS Res. Hum. Retroviruses 10: 279-284.

32. Charron D, (ed). (1997) Proceedings of the 12th IHWC. HLA Genetic diversity of HLA Functional and Medical Implication. Paris: EDK, Medical and Scientific International Publisher. 